\title{
A emergência da pesquisa da História das Mulheres e das Relações de Gênero
}

\author{
The emergence of the research on \\ Women's History and Gender Relations
}

\author{
Rachel Soihet* \\ Joana Maria Pedro**
}

\section{RESUMO}

A trajetória da formação do campo historiográfico intitulado "História das Mulheres e das Relações de Gênero" no Brasil, é o que pretendemos abordar neste artigo. Para tanto, focalizamos as obras publicadas a partir da década de 1980 , as pesquisas realizadas e as categorias de análise utilizadas, visando traçar um panorama da constituição desse campo. Mostramos, também, a forma como as categorias 'mulher', 'mulheres' e 'relações de gênero' têm sido alvo de discussões, apropriações e disputas.

Palavras-chave: história das mulheres; relações de gênero; historiografia.

\section{ABSTRACT}

In this article we discuss the trajectory of the formation of the historiography of "The History of Women and Gender Relations" in Brazil. To this end we have focused on works published from the 1980s on; on the research carried out; and on the categories of analysis used to try to draw a panorama of the formation of this discipline. We also show the way in which the categories 'Woman', 'Women' and 'Gender Relations' have been the target of discussions, appropriations and disputes.

Keywords: women's history; gender relation; historiography.

Em 1989, a Revista Brasileira de História publicou um número inteiramente dedicado ao tema da Mulher, intitulado "A mulher no espaço público" (v.9, n.18) e organizado por Maria Stella Martins Bresciani. Em sua apresentação, a organizadora dizia ser esta uma "história da exclusão". Falar de Mulher na história significava, então, tentar reparar em parte essa exclusão, uma

\footnotetext{
* Pós-Graduação em História, Universidade Federal Fluminense (UFF), Campus de Gragoatá, s/n, Bloco O, sala 503, Gragoatá. 24210-350 Niterói - RJ - Brasil. rachelsoihet@globo.com.

** Departamento de História, Centro de Filosofia e Ciências Humanas, Universidade Federal de Santa Catarina (UFSC), Campus Universitário, Trindade, C.P. 476. 88040-900 Florianópolis - SC - Brasil. joanamaria.pedro@gmail.com.
} 
vez que procurar traços da presença feminina em um domínio sempre reservado aos homens era tarefa difícil. Nesse número, categorias como 'mulher', 'mulheres' e 'condição feminina' eram utilizadas nas análises das fontes e nas narrativas que eram tecidas. A categoria 'gênero' ainda era novidade na historiografia brasileira.

Hoje, 18 anos depois daquele número, outras questões se apresentam. Tentamos, neste artigo, nomear e fornecer datas para as mudanças ocorridas. Queremos refletir sobre a historicidade de nossas categorias de análise, e, ao mesmo tempo, mostrar que já não se trata de reparar uma exclusão. O que precisamos é buscar formas mais eficientes de fornecer legitimidade ao que temos feito, ou seja, a constituição de um novo campo de estudos, intitulado "História das $\mathrm{Mu}$ lheres e das Relações de Gênero".

Convém lembrar que antes de surgir aquele número da Revista Brasileira de História, Maria Odila Leite da Silva Dias já havia publicado, em 1984, o seu livro Quotidiano e poder em São Paulo no século XIX, e nele a categoria 'mulheres' estava presente. Além dela, Luzia Margareth Rago publicou, em 1985, Do cabaré ao lar: a utopia da cidade disciplinar, Brasil 1890-1930; Miriam Moreira Leite tinha organizado, em 1984, também, A condição feminina no Rio de Janeiro, século XIX: antologia de textos de viajantes estrangeiros. ${ }^{1} \mathrm{E}$, no mesmo ano do citado número da RBH (1989), outras autoras estavam publicando, como por exemplo Martha de Abreu Esteves, em Meninas perdidas: os populares e o cotidiano do amor no Rio de Janeiro da Belle Époque; Rachel Soihet, em Condição feminina e formas de violência: mulheres pobres e ordem urbana, 1890-1920; Eni de Mesquita Samara, As mulheres, o poder e a família: São Paulo século XIX; Magali Engel, Meretrizes e doutores: saber médico e prostituição no Rio de Janeiro. ${ }^{2}$ Portanto, o número da RBH emergiu no interior de várias pesquisas que estavam tematizando aquelas categorias.

Foi no ano seguinte, ou seja, em 1990, que a Revista Educação e Realidade publicou a tradução de um artigo da historiadora norte-americana Joan Scott: "Gênero: uma categoria útil de análise histórica". Esse tem sido, certamente, um dos mais citados, nas discussões que pretendem abordar a categoria 'gênero' nas análises da pesquisa histórica. Evidentemente, não foi esse o único texto no Brasil a instruir as pesquisas que queriam se aventurar por esse novo campo. Historiadoras brasileiras fizeram seus ensaios que muito auxiliaram na reflexão, ao longo destes anos. ${ }^{3}$

Além de pesquisas que se aventuraram pela categoria 'gênero', outras continuaram a discutir a 'mulher', ou ainda 'mulheres'. Houve, na constituição desse campo de conhecimento historiográfico, iniciativas que agregaram pes- 
quisadoras ${ }^{4}$ interessadas no tema. A constituição de um Grupo de Trabalho de Estudos de Gênero, visando articular em âmbito nacional uma rede de contatos entre pesquisadoras, articulado à Associação Nacional de História, foi criado em 25 de julho de 2001, durante o XXI Simpósio Nacional da Anpuh, realizado em Niterói (RJ). Na ocasião, Rachel Soihet foi eleita Coordenadora Nacional do GT (Grupo de Trabalho) Estudos de Gênero. Outros GTs de Estudos de Gênero, de âmbito regional, foram criados em São Paulo, em Santa Catarina e, mais tarde, no Rio Grande do Sul, no Rio de Janeiro e em Dourados, no Mato Grosso do Sul. Essa articulação de GTs tem garantido que, nas diversas reuniões nacionais da Associação Nacional de História, os Simpósios Temáticos que discutem 'gênero' apresentem um número significativo de trabalhos, mostrando a vitalidade do campo em construção. Ainda convém destacar que, periodicamente, o GT Estudos de Gênero tem feito reuniões de âmbito nacional, seja em Simpósios Regionais da Anpuh, como o de Santa Catarina em 2002 e o de São Paulo em 2006, seja nos Simpósios Nacionais, a cada dois anos. No último Simpósio Nacional da Anpuh, realizado em 2007 em São Leopoldo, no Rio Grande do Sul, a coordenação do GT Estudos de Gênero (Nacional) foi transferida para Joana Maria Pedro. Nesse evento, o GT Estudos de Gênero da ANPUH participou da programação geral do evento com dois simpósios temáticos - "Gênero, Memória e Ditadura na América latina", coordenado por Cristina Scheibe Wolff e Ana Maria Colling; e "Gênero, Poder e Representações Sociais”, coordenado por Rachel Soihet e Lídia Maria Vianna Possas - e, ainda, com um mini-curso: "Relações de gênero no Ensino e na Pesquisa histórica”, ministrado por Joana Maria Pedro e Temis Gomes Parente.

A vitalidade deste campo de conhecimentos extrapola as reuniões da Associação Nacional de História. Está presente, também, por exemplo, nas reuniões da Associação Nacional de História Oral, na qual um GT de gênero tem marcado presença desde 2002. Ainda em outras reuniões científicas, como a Anpocs (Associação Nacional de Pós-Graduação e Pesquisa em Ciências Sociais), realizado todos os anos em Caxambu, Minas Gerais, e o FAZENDO GÊNERO - este realizado a cada dois anos em Florianópolis, Santa Catarina. Tem sido numerosa a presença de historiadoras em todos esses eventos, mostrando, assim, um diálogo muito fértil realizado de forma interdisciplinar.

Muitos dos trabalhos historiográficos apresentados nesses eventos científicos, especialmente os da Associação Nacional de História, têm sido publicados em dossiês de revistas especializadas em História das Mulheres e Estudos de Gênero, como os periódicos Revista Estudos Feministas, Espaço Feminino 
e Gênero; mas, também em revistas que não são dedicadas a esses temas, como a Revista Esboços, a Revista ArtCultura, a Revista Fronteiras e, agora, a Revista Brasileira de História.

A fertilidade dos dias atuais contrasta, entretanto, com a trajetória difícil que a categoria de análise 'gênero' enfrentou no campo historiográfico. Nas ciências humanas, a disciplina História é certamente a que mais tardiamente apropriou-se dessa categoria, assim como da própria inclusão de 'mulher' ou de 'mulheres' como categoria analítica na pesquisa histórica. A trajetória, costumeiramente 'cautelosa', dessa disciplina, e o domínio do campo por determinadas perspectivas de abordagem, retardaram significativamente o avanço das discussões. Grande parte desse retardo se deveu ao caráter universal atribuído ao sujeito da história, representado pela categoria 'homem'. Acreditava-se que, ao falar dos homens, as mulheres estariam sendo, igualmente, contempladas, o que não correspondia à realidade. Mas, também, não eram todos os homens que estavam representados nesse termo: via de regra, era o homem branco ocidental. Tal se devia à modalidade de história que se praticava, herdeira do Iluminismo. Genericamente conhecida como positivista, centrava o seu interesse na história política e no domínio público, e predominou no século XIX e inícios do XX. Esta privilegiava fontes administrativas, diplomáticas e militares, nas quais as mulheres pouco apareciam. Era a "história de governantes e de batalhas", segundo a historiadora Elizabeth Fox Genovese. ${ }^{5}$

Em contraposição a essa modalidade de história, observa-se, ainda, a partir da década de 1920, a emergência do grupo dos Annales, representado por Marc Bloch e Lucien Febvre. Diversamente da historiografia vigente, direcionam seu interesse para a história de seres vivos, concretos, e à trama de seu cotidiano, ao invés de se ater a uma racionalidade universal. À medida que a tradição historiográfica dos Annales propunha ampliar o leque de fontes e observar a presença de pessoas comuns, ela contribuiu para que as mulheres, posteriormente, fossem incorporadas à historiografia. $\mathrm{O}$ marxismo constituiu-se em outra corrente que assumiu posição significativa na historiografia. Majoritariamente, seus seguidores privilegiaram as contradições de classe, considerando secundárias as questões étnicas, assim como a problemática que opõe homens e mulheres. Essa se resolveria com o fim da contradição principal: a instauração da sociedade sem classes. Não se justificava, portanto, uma atenção especial do/a historiador/a para a questão feminina.

Durante a década de 1960, cresceu na historiografia um movimento, crítico do racionalismo abstrato, que relativizou a importância de métodos ou de conceitos teóricos rígidos. Silva Dias discorreu sobre a questão, assinalan- 
do o desdobramento desse movimento em várias correntes: revisionismo neomarxista, Escola de Frankfurt, historistas, historiadores das mentalidades e do discurso, no sentido da desconstrução de Derrida ou na linha de Foucault. O conhecimento histórico tornou-se relativo, tanto a uma determinada época do passado, como a uma dada situação do historiador no tempo, o qual procura interpretar os processos de mudança através de um conhecimento dialético. Tal panorama tornou mais factível a integração da experiência social das mulheres na história, já que sua trama é tecida basicamente a partir do cotidiano, e não de pressupostos rígidos e de grandes marcos (Silva Dias, 1992, p.43-44).

Nesse particular, destaca-se o vulto assumido pela história social, na qual se engajam correntes revisionistas marxistas, cuja preocupação incide sobre as identidades coletivas de uma ampla variedade de grupos sociais, até então excluídos do interesse da história: operários, camponeses, escravos, pessoas comuns. Pluralizam-se os objetos de investigação histórica, e, nesse bojo, as mulheres são alçadas à condição de objeto e sujeito da história. A preocupação da corrente neomarxista com a inter-relação entre o micro e o contexto global permite a abordagem do cotidiano, dos papéis informais e das mediações sociais - elementos fundamentais na apreensão das vivências desses grupos, de suas formas de luta e de resistência. Ignorados num enfoque marcado pelo caráter totalizante, tornam-se perceptíveis numa análise que capte o significado de sutilezas, possibilitando o desvendamento de processos de outra forma invisíveis.

O desenvolvimento de novos campos tais como a história das mentalidades e a história cultural reforça o avanço na abordagem do feminino. Apóiam-se em outras disciplinas - tais como a literatura, a lingüística, a psicanálise e, principalmente, a antropologia -, com o intuito de desvendar as diversas dimensões desse objeto. Assim, a interdisciplinaridade assume importância crescente nos estudos sobre as mulheres.

Dessa forma, as transformações na historiografia, articuladas à explosão do feminismo, a partir de fins da década de 1960, tiveram papel decisivo no processo em que as mulheres são alçadas à condição de objeto e sujeito da História, marcando a emergência da História das Mulheres. Nos Estados Unidos, onde se desencadeou o referido movimento, bem como em outras partes do mundo nas quais ele se apresentou, as reivindicações das mulheres provocaram uma forte demanda por informações, pelas estudantes, acerca de questões que estavam sendo discutidas. Ao mesmo tempo, docentes mobilizaram-se, propondo a instauração de cursos, nas universidades, dedicados 
aos estudos das mulheres. Como resultado dessa pressão, criaram-se nas universidades francesas, a partir de 1973, cursos, colóquios e grupos de reflexão, surgindo um boletim de expressão focalizando o novo objeto: Penélope. Cahiers pour l'histoire des femmes. Multiplicaram-se as pesquisas, tornando-se a história das mulheres, dessa forma, um campo relativamente reconhecido no âmbito institucional.

$\mathrm{Na}$ Inglaterra, reuniram-se as historiadoras das mulheres em torno da History Workshop, e nos Estados Unidos desenvolveram-se os Women's Studies, surgindo as revistas Signs e Feminist Studies. ${ }^{6}$ Também no Brasil, esses estudos se apresentaram ainda na década de 1970. Assim, em julho de 1975, o jornal alternativo Opinião noticiava o elevado número de pesquisas sobre as mulheres brasileiras apresentadas na XXVII Reunião da SBPC, realizada em Belo Horizonte. O mesmo jornal informa a apresentação de dez comunicações de pesquisa, dois simpósios, uma conferência e duas reuniões extras, surgidas da necessidade de se discutir mais o assunto. ${ }^{7}$

Constituída a História das Mulheres, de acordo com Joan Scott, uma das mais importantes contribuições das historiadoras feministas foi o descrédito das correntes historiográficas polarizadas para um sujeito humano universal. Em que pesem seus esforços no sentido de acomodar as mulheres numa história que, de fato, as excluía, a contradição instaurada revelou-se fatal. A história das mulheres - com suas compilações de dados sobre as mulheres no passado, com suas afirmações de que as periodizações tradicionais não funcionavam quando as mulheres eram levadas em conta, com sua evidência de que as mulheres influenciavam os acontecimentos e tomavam parte na vida pública, com sua insistência de que a vida privada tinha uma dimensão pública - implicava a negação de que o sujeito da história constituía-se numa figura universal.

Ainda de acordo com Joan Scott, tais experiências iniciais de inclusão das mulheres no ser humano universal trouxeram à tona uma situação plena de ambigüidades. Afinal, a solicitação de que a história fosse suplementada com informações sobre as mulheres equivalia a afirmar não só o caráter incompleto daquela disciplina, mas também que o domínio que os historiadores tinham do passado era parcial. Fato, este, necessariamente demolidor para uma realidade que definia a "história e seus agentes já estabelecidos como 'verdadeiros', ou pelo menos, como reflexões acuradas sobre o que teve importância no passado" (Scott, 1992, p.86, 77).

Nesse processo, foram fundamentais as contribuições recíprocas entre a história das mulheres e o movimento feminista. Os historiadores sociais, por 
exemplo, supuseram as 'mulheres' como uma categoria homogênea; eram pessoas biologicamente femininas que se moviam em papéis e contextos diferentes, mas cuja essência não se alterava. Essa leitura contribuiu para o discurso da identidade coletiva, que favoreceu o movimento das mulheres na década de 1970. Firmou-se o antagonismo 'homem versus mulher' como um foco central na política e na história, que favoreceu uma mobilização política importante e disseminada. Já no final da década, porém, tensões instauraramse, quer no interior da disciplina, quer no movimento político. Essas tensões teriam se combinado para questionar a viabilidade da categoria 'mulheres' e para introduzir a 'diferença' como um problema a ser analisado. Inúmeras foram as contradições que se manifestaram, demonstrando a impossibilidade de se pensar uma identidade comum. A fragmentação de uma idéia universal de 'mulheres' por classe, raça, etnia, geração e sexualidade associava-se a diferenças políticas sérias no seio do movimento feminista. Assim, de uma postura inicial em que se acreditava na possível identidade única entre as mulheres, passou-se a outra, em que se firmou a certeza na existência de múltiplas identidades.

Mulheres negras, índias, mestiças, pobres, trabalhadoras, muitas delas feministas, reivindicaram uma 'diferença' - dentro da diferença. Ou seja, a categoria 'mulher', que constituía uma identidade diferenciada da de 'homem', não era suficiente para explicá-las. Elas não consideravam que as reivindicações as incluíam. Não consideravam, como fez Betty Friedan, na Mística feminina, ${ }^{8}$ que o trabalho fora do lar, a carreira, seria uma 'libertação'. Essas mulheres havia muito trabalhavam dentro e fora do lar. O trabalho fora do lar era, para elas, apenas uma fadiga a mais. Além disso, argumentavam, o trabalho 'mal remunerado', que muitas mulheres brancas de camadas médias reivindicavam como forma de satisfação pessoal, poderia ser o emprego que faltava para seus filhos, maridos e pais. ${ }^{9}$

Assim, o enfoque na diferença desnudou a contradição flagrante da história das mulheres com os pressupostos da corrente historiográfica polarizada para um sujeito humano universal, dando lugar ao questionamento daqueles pressupostos que norteavam as ciências humanas (Scott, 1992, p.81-88). Além disso, revelavam-se múltiplas diferenças dentro da diferença, ou seja, entre mulheres, como entre homens, embora não se pudesse esquecer as desigualdades e relações de poder entre os sexos.

Na historiografia, inúmeras pesquisas, na década de 1980, partiam da categoria 'mulheres'. Nessa trilha, muitas pesquisadoras e pesquisadores têm procurado destacar as vivências comuns, os trabalhos, as lutas, as sobrevivên- 
cias, as resistências das mulheres no passado. Destacaram-se, ainda, no plano internacional da historiografia, nos anos que se seguiram, os nomes de Michelle Perrot, ${ }^{10}$ Georges Duby, Françoise Thébaud, Joan Scott, June Hahner, Natalie Zemon Davis, para citar as estrangeiras, e de Maria Odila da Silva Dias, Margareth Rago, Miriam Moreira Leite, Rachel Soihet, Martha de Abreu Esteves, Mary Del Priore, Eni de Mesquita Samara, Leila Algranti, Maria Lucia de Barros Mott de Melo e Souza, Maria Izilda Santos de Matos, Luciano Figueiredo, Temis Parente, Lídia Viana Possas, Joana Maria Pedro, Lená Medeiros de Menezes, Magali Engel e Suely Gomes Costa, ${ }^{11}$ para citar algumas das brasileiras. $^{12}$

Para a historiografia brasileira, de acordo com Mônica Raisa Schpun, Maria Odila Leite da Silva Dias foi uma das precursoras. ${ }^{13}$ Assim, além de ser autora de um dos trabalhos que mais influenciaram a História das Mulheres no Brasil, o livro Quotidiano e poder, essa autora tem sido a formadora de toda uma geração de historiadoras das mulheres e das relações de gênero. Evidentemente, outras historiadoras também têm sido responsáveis pela formação de profissionais nesse campo; entretanto, a autora destaca-se pelo pioneirismo. ${ }^{14}$

E as relações de gênero? Qual sua importância? Como tem sido trabalhada na historiografia brasileira? Como já dissemos, data de 1990 a publicação do artigo fundador de Joan Scott. Mas, afinal, por que 'gênero'? Essa categoria foi tomada de empréstimo à gramática. Em seu sentido original, gênero é o fenômeno da presença em algumas línguas (por exemplo, as indo-européias) de desinências diferenciadas para designar indivíduos de sexos diferentes ou ainda coisas sexuadas. Gênero, nas ciências sociais, tomou outra conotação, e significa a distinção entre atributos culturais alocados a cada um dos sexos e a dimensão biológica dos seres humanos. O grande impacto que vem produzindo nas análises sociais funda-se em ter chamado a atenção para o fato de que uma parte da humanidade estava na invisibilidade - as mulheres -, e seu uso assinala que, tanto elas quanto os homens são produto do meio social, e, portanto, sua condição é variável.

Além disso, 'gênero' dá ênfase ao caráter fundamentalmente social, cultural, das distinções baseadas no sexo, afastando o fantasma da naturalização; dá precisão à idéia de assimetria e de hierarquia nas relações entre homens e mulheres, incorporando a dimensão das relações de poder; dá relevo ao aspecto relacional entre as mulheres e os homens, ou seja, de que nenhuma compreensão de qualquer um dos dois poderia existir através de um estudo que os considerasse totalmente em separado, aspecto essencial para "descobrir a 
amplitude dos papéis sexuais e do simbolismo sexual nas várias sociedades e épocas, achar qual o seu sentido e como funcionavam para manter a ordem social e para mudá-la”. Estas foram algumas de suas contribuições. Acresce-se a significação, emprestada por esses estudos, à articulação do gênero com a classe e a raça/etnia. Interesse indicativo não apenas do compromisso com a inclusão da fala dos oprimidos, mas também da conviç̧ão de que as desigualdades de poder se organizam, no mínimo, conforme esses três eixos. ${ }^{15} \mathrm{Na}$ realidade, como enfatiza Suely Gomes Costa, torna-se possível, com relação a tal conceito, "intuí-lo como um código-chave inventado para superar impasses a que a história das mulheres havia chegado” (Costa, 2003, p.188).

Joan Scott alinha-se entre as historiadoras que se propunham a ultrapassar os usos descritivos do gênero, buscando a utilização de formulações teóricas. Uma voz dissonante, nesse particular, foi a da historiadora Maria Odila Leite da Silva Dias, que discordou da necessidade da construção imediata de uma teoria feminista. A seu ver, tal reconstrução significava substituir um sistema de dominação cultural por outra versão das mesmas relações, talvez invertidas de poder, já que, segundo ela, o saber teórico implicaria, também, um sistema de dominação (Silva Dias, 1992, p.39).

Scott argumentava que, no seu uso descritivo, o gênero é apenas um conceito associado ao estudo das coisas relativas às mulheres, mas não tem a força de análise suficiente para interrogar e mudar os paradigmas históricos existentes. Ressalta, também, a defasagem entre a alta qualidade dos trabalhos da história das mulheres e seu estatuto, que permanece marginal em relação ao conjunto da disciplina - o que poderia ser aquilatado pelos manuais, programas universitários e monografias. Ficam assim, segundo Scott, demonstrados os limites das abordagens descritivas que não questionam os conceitos dominantes no seio da disciplina ou, pelo menos, não os questionam de forma a abalar o seu poder e talvez transformá-los. Assim, não teria sido suficiente aos historiadores das mulheres provar que elas tiveram uma história ou que as mulheres participaram das mudanças políticas principais da civilização ocidental. Após um reconhecimento inicial, a maioria dos historiadores descartou a história das mulheres ou colocou-a em um domínio separado: "as mulheres têm uma história separada da dos homens, portanto deixemos as feministas fazer a história das mulheres que não nos concerne necessariamente". Quanto à participação das mulheres na história, a reação foi de um interesse mínimo: "a compreensão de um determinado acontecimento, a Revolução Francesa, por exemplo, não mudou com a descoberta de que as mulheres dela participaram". Esse tipo de reação encerra, segundo Scott, um desafio 
teórico. Ele exige a análise não só da relação entre experiências masculinas e femininas no passado, mas também a ligação entre a história do passado e as práticas históricas atuais (Scott, 1991, p.3).

Scott ressalta, ainda, que as análises do gênero, no seu uso descritivo, têm incidido apenas nos trabalhos sobre temas em que a relação entre os sexos é mais evidente: as mulheres, as crianças e as famílias, por exemplo. Aparentemente, temas como a guerra, a diplomacia e a alta política não teriam a ver com essas relações. O gênero parece não se aplicar a esses objetivos e, portanto, continua irrelevante para a reflexão dos historiadores que trabalham sobre o político e o poder. O resultado é a adesão a uma visão funcionalista baseada na biologia, e a perpetuação da idéia das esferas separadas na escrita da história: a sexualidade ou a política, a família ou a nação, as mulheres ou os homens.

Com base nessas reflexões, Scott apresenta sua proposta teórica, com vistas à explicação do conceito de gênero e de como as relações entre os sexos estruturaram-se ao longo da história. Consta, a referida proposta, de duas partes: de um lado, o gênero é um elemento constitutivo de relações sociais baseado nas diferenças percebidas entre os sexos; de outro lado, o gênero é uma forma primeira de significar as relações de poder. As mudanças na organização das relações sociais correspondem, sempre, à mudança nas representações de poder, mas a direção da mudança não segue necessariamente um sentido único.

Em suma, sua proposta de teorização sobre 'gênero' seria motivada pelo mesmo objetivo que levara as historiadoras feministas, particularmente as francesas, a escreverem a história das mulheres, qual seja, o de "apontar e modificar as desigualdades entre homens e mulheres". Nesse sentido, propõe uma análise sobre como "as hierarquias de gênero são construídas e legitimadas". ${ }^{16}$

Para responder a essa questão, Scott apóia-se nos pós-estruturalistas, que se preocupam com o significado, pois enfatizam a variedade e a natureza política deste. Dessa perspectiva, propõe que a história seja escrita "a respeito de como os significados subjetivos e coletivos de homens e mulheres, como categorias de identidade, foram construídos". Para quem quer escrever esta história, trata-se de observar os significados "variáveis e contraditórios" que são atribuídos à diferença sexual.

Finaliza argumentando que um conceito relativizado de gênero, como um saber historicamente específico sobre a diferença sexual, permite, às feministas, forjar um instrumento analítico que possibilita gerar um conhecimento novo sobre as mulheres e sobre a diferença sexual, e inspirar desafios 
críticos às políticas da história ou de qualquer outra disciplina. A história feminista deixa, então, de ser apenas uma tentativa de corrigir ou suplementar um registro incompleto do passado, e se torna um modo de compreender criticamente como a história opera enquanto lugar de produção do saber de gênero. Esclarece que esse saber era pensado no sentido a ele atribuído por Michel Foucault, ou seja, sempre relativo: seus usos e significados "nascem de uma disputa política e são os meios pelos quais as relações de poder - de dominação e de subordinação - são construídas". Ainda, concluía Scott, "gênero é a organização social da diferença sexual”. Lembrava, porém, que gênero não refletia ou implementava diferenças fixas e naturais entre homens e mulheres, mas "um saber que estabelece significados para as diferenças corporais" (Scott, 1994, p.12-13, 25).

$\mathrm{Na}$ historiografia brasileira, muitas têm sido as pesquisadoras a utilizar a categoria 'gênero'. Foi dessa maneira que Cleci Eulália Favaro, falando das famílias italianas que migraram para o Rio Grande do Sul, mostrou o estabelecimento de hierarquias no significado do que era ser 'feminina' entre sogras e noras. Ou seja, o que Cleci focalizou foi a relação de gênero entre mulheres. Neste caso, a sogra, na relação de poder com a nora, mostrava-lhe o quanto ela era "muito mais mulher" do que esta. ${ }^{17}$

Rachel Soihet apontou a forma como o anti-feminismo atua na constituição do gênero. ${ }^{18}$ Maria Bernardete Ramos Flores observou, nas décadas de 1920 e 1930, o reforço do gênero através dos discursos que enfatizavam a maternidade nas campanhas de regeneração nacional que se vinculavam à eugenia e à higiene. ${ }^{19} \mathrm{E}$, no Rio Grande do Sul, Aurea Tomatis Petersen, ${ }^{20}$ por exemplo, mostrou, em sua tese de doutorado, como as mulheres entraram no Banco do Brasil durante a Segunda Guerra Mundial, em substituição aos homens que foram para a guerra, mudando, assim, a relação de poder no interior do Banco. Marlene de Faveri, em sua tese de doutorado, narra como homens e mulheres de diferentes etnias envolveram-se de maneira diferenciada com o cotidiano da guerra, em Santa Catarina. Mostra como a guerra teve um significado diferente para cada pessoa, em vista do gênero e da etnia. ${ }^{21}$

Por sua vez, várias autoras, tais como Margareth Rago, Maria Izilda Matos, Cristina Scheibe Wolff, Roselane Neckel, Tania Navarro-Swain e Mônica Schpun, ${ }^{22}$ entre outras, têm contribuído para o conhecimento da história das relações de gênero, focalizando a maneira como o gênero se constitui num ponto de apoio para constituições de subjetividades, políticas públicas e relações com a história. E, ainda dentro dessas mesmas discussões, Durval de Albuquerque Jr. vem dando historicidade às masculinidades no Nordeste. ${ }^{23}$ 
Mas, para além de todas essas discussões, uma nova mudança ocorreu nesse panorama das relações de gênero com as reflexões de Thomas Laqueur, o qual, contrariamente às concepções que antepunham o sexo ao gênero, como aquela de Scott, afirmava que o gênero constituía o sexo. Baseava-se, essa colocação, naquilo que chamou "invenção moderna de dois sexos distintos", ocorrida, mais precisamente, no século XVIII. Até então se acreditava na homologia dos órgãos genitais, cuja diferença pensava-se residir apenas em estar oculto nas mulheres o que nos homens era aparente. O que não significava, porém, que a indiferenciação sexual, na ordem natural, implicasse igualdade na ordem social. "Um sexo, portanto, mas dois gêneros assimétricos", como bem resume Colette St. Hilaire. ${ }^{24} \mathrm{O}$ reconhecimento de diferenças entre o corpo masculino e o feminino, considerando-se a especificidade do corpo feminino, demonstrava que as relações de gênero é que instituíram o sexo, concluindo Laqueur: "O sexo, tanto no mundo do sexo único como no de dois sexos, é situacional: é explicável apenas dentro do contexto de luta sobre gênero e poder". 25

Nessa vertente, também divergindo das posições que sobrepunham o gênero ao sexo biológico, ressaltam-se as formulações da filósofa Judith Butler, que revelam certo distanciamento daquelas concepções acima apresentadas. Contrapõe-se às diversas conceitualizações que pensam as identidades como fixas, em termos de gênero/sexo, mulheres/homens, sujeito/outro. Sua proposta, na perspectiva de Foucault, reside em se pensar como foi construída a dualidade sexual, ou seja, como os diversos discursos científicos produziram essa dualidade discursivamente. Através desse procedimento o sexo aparece como culturalmente construído. Nesse sentido, esboroa-se a concepção de gênero como inscrição cultural de significado sobre um sexo naturalmente dado.

Quando o status construído do gênero é teorizado como radicalmente independente de sexo, o próprio gênero se torna um artifício flutuante com a conseqüência de que homem e masculino podem, com igual facilidade, significar tanto um corpo feminino como um masculino, e mulher e feminino, tanto um corpo masculino como um feminino. ${ }^{26}$

De acordo com a autora, é necessário reformular gênero, de forma que possa conter as relações de poder que produzem o efeito de um sexo pré-discursivo. Gênero seria estilização repetida do corpo, um conjunto de atos reiterados dentro de um marco regulador altamente rígido, que se congela no tempo, produzindo a aparência de uma substância. Mas esses atos e gestos seriam performáticos, no sentido de que a essência ou a identidade que supostamente 
expressam são construções manufaturadas e sustentadas através de signos corporais e de outros meios. Em sua perspectiva, 'gênero' poderia ser considerado como um ato intencional e, ao mesmo tempo, performático, no sentido de construção dramática e contingente de significado. ${ }^{27}$ Em suma, a 'performatividade' do gênero é um efeito discursivo, e o sexo é um efeito do gênero.

E, confirmando Butler, a historiadora Tania Navarro-Swain declara: “o gênero cria, portanto, o sexo, e não o contrário".

Isso não significa que não existam corpos humanos sexuados, com um aparelho genital dado. O que é criado pelas redes de significação e pelas práticas sociais é a importância dada a esse fator, é a significação que lhe é atribuída enquanto revelador, catalisador da essência do ser e da identidade do indivíduo. É o sexo que aparece enquanto efeito discursivo, dando forma e perfil ao feminino/masculino binário, pela atribuição de valores a certos detalhes anatômicos.

A difusão desses referenciais teóricos contribuiu para a abertura de linhas de pesquisa e reflexão sobre gênero não centradas nas mulheres. Ressalte-se a produção de estudos sobre masculinidade e, também, os estudos queer, para os quais a obra de Butler é altamente inspiradora. ${ }^{28}$

Linda Nicholson é outra pesquisadora que, seguindo as discussões de Foucault, Laqueur e Butler, lembra que separar sexo de gênero e considerar o primeiro como essencial para elaboração do segundo, pode ser, como queriam as feministas da década de 1970, uma forma de fugir ao determinismo biológico, mas constitui-se, por sua vez, num "fundacionalismo biológico". Isto porque "postula uma relação mais do que acidental entre a biologia e certos aspectos de personalidade e comportamento". ${ }^{29} \mathrm{Ou}$ seja, "funda", sobre o biológico, aquilo que a cultura estabelece como personalidade e comportamento de homens e mulheres.

Uma das bases da formulação da oposição sexo/gênero foi o clássico artigo de Gayle Rubin, “The Traffic of Women”, no qual a autora apresentou o conceito de "sistema sexo/gênero", relativo ao "conjunto de acordos sobre os quais a sociedade transforma a sexualidade biológica em produtos da atividade humana... ${ }^{30}$ Assim, o sexo, nesse modelo explicativo, permaneceria como a base à qual seriam atribuídos significados culturais, emblema do fundacionalismo biológico, já que apresenta um aspecto comum ao determinismo biológico; mas, em contraste com este, os dados da biologia coexistem com aspectos da personalidade e do comportamento.

Para resolver o dilema, Nicholson acentua a necessidade de o feminismo 
abandonar o fundacionalismo biológico junto com o determinismo biológico, pois:

A população humana difere, dentro de si mesma, não só em termos das expectativas sociais sobre como pensamos, sentimos e agimos; há também diferenças nos modos como entendemos o corpo. O corpo se torna uma variável, mais do que uma constante, não mais capaz de fundamentar noções relativas à distinção masculino/feminino, através de grandes varreduras da história humana, mas sempre presente como elemento potencialmente importante na forma como a distinção masculino/feminino permanece atuante em qualquer sociedade. (Nicholson, 2000, p.14-15)

Ainda Tania Navarro-Swain, inspirada em Foucault, sugere a busca de um nomadismo identitário: "Nada de representações fixas: uma identidade nômade não compreende senão o movimento, a transformação, a crítica que se inicia com a auto-representação sexuada e se estende ao social" (NavarroSwain, 2000, p.77).

No âmbito das discussões feministas, porém, as formulações desconstrutivistas têm provocado reações negativas. Essas reações convergem em assinalar as incompatibilidades entre tais abordagens e a prática política feminista - "gênero sem mulheres?”. Mostram questionamentos à 'despolitização' da pesquisa acadêmica, e um acirramento de tensões entre produção teórica e mobilização política. Seus argumentos possibilitam a compreensão do contexto, no qual algumas autoras propõem uma nova utilização da categoria 'mulher'.

Tais perspectivas desconstrutivistas, em sua busca de desessencialização, são criticadas por dissolver o sujeito político mulheres, e por restabelecerem distâncias entre a reflexão teórica e o movimento político. Em que pesem as críticas a estas correntes, por sua excessiva ênfase nas diferenças, as feministas, porém, reconhecem a utilidade de uma série de trabalhos informados por tais perspectivas. Dentre os trabalhos positivamente considerados, ressalta-se a produção que discute a interseção gênero/raça - uma vez que, embora desenvolvendo argumentos teóricos, tende a responder perguntas concretas - e os trabalhos sobre multiculturalismo. Essas críticas reconhecem, também, que tais perspectivas teóricas, quando operam com um foco internacional, enfatizam a compreensão da diferença, evitando a construção do outro como um 'exótico'.

Assim, essas discussões não são marcadas apenas por leituras negativas do desconstrutivismo. Nelas há, também, ambivalências em relação a tais abordagens, uma vez que possibilitam pôr em destaque as diferenças. Essas ambi- 
valências fazem sentido quando se pensa que, se o projeto feminista está ancorado na 'modernidade', ele também está marcado por uma tensão entre o universal e o particular. As críticas às abordagens desconstrutivistas também evidenciam confusões, no que se refere ao significado de 'fazer teoria'. Nesse marco de ambivalências e confusões algumas autoras 'abandonam' gênero, propondo uma nova utilização da categoria 'mulher' (Piscitelli, 2004, p.58).

A idéia de 'mulher', agora proposta, apresentar-se-ia, porém, distante das elaborações do feminismo radical da década de 1970, isto é, longe de qualquer tipo de essencialismo. Discorrendo sobre a questão, Adriana Piscitelli conclui que ela não se situa (exclusivamente) no plano do conhecimento. $\mathrm{O}$ sentido da re-criação da categoria mulher seria, sobretudo, político. Linda Nicholson seria uma das suas mentoras e, em sua opinião, a categoria 'mulher', nos termos que propõe, apresenta uma dupla vantagem. Possibilita o reconhecimento de diferenças entre mulheres, mas, uma vez que também permite mapear semelhanças, não inviabilizaria a prática política - que segundo a autora não exige um sentido definido para o termo mulher. Tratar-se-ia de políticas de coalizão - compostas por listas de reivindicações relativas às diferentes necessidades dos grupos que constituem, temporariamente, a coalizão (Piscitelli, 2004, p.59).

O conteúdo político dessa categoria é sublinhado de maneira mais explícita por Claudia de Lima Costa, uma das autoras que propõem sua utilização no contexto do Brasil. Costa resgata abertamente as contribuições do pósestruturalismo para a teoria feminista, a partir dos ganhos trazidos pelo conceito de gênero. Segundo essa autora, trata-se da negação epistemológica de qualquer tipo de essência à mulher. Trata-se, também, de possibilitar teorizar com mais destreza as complexas e fluidas relações e tecnologias de poder. Paradoxalmente, no que se refere à construção do conhecimento, insiste na re-criação da categoria 'mulher' abandonando a utilização do gênero. Esse retorno à noção de mulher é justificado a partir de sua consideração explícita como categoria política, uma vez que os usos perversos do conceito de gênero tê-lo-iam, às vezes, transformado em masculinidade. Nessa perspectiva, argumenta Costa que:

a 'mulher' é uma categoria heterogênea, construída historicamente por discursos e práticas variados, sobre os quais repousa o movimento feminista. Dependendo do contexto conjuntural e das exigências políticas, esta categoria é usada para articular as mulheres politicamente. Contudo, ela possui diferentes tempo- 
ralidades e densidades, existindo em relação a outras categorias igualmente instáveis. $^{31}$

Ou seja, aceitar a instabilidade semântica da 'mulher' significa o que já é evidente para o feminismo: "que a história e o significado de uma categoria devem ser entendidos à luz das histórias e significados das outras categorias de identidade (classe, raça, etnia, sexualidade, nacionalidade etc.)" (Costa, 1998, p.138).

Nesse sentido, as tensões entre o movimento político e a teoria são, mais uma vez, demonstradas, o que tem contribuído para o desenvolvimento e reformulação do conceito de gênero. Ainda na década de 1980, Joan Scott referia-se à oposição a esse conceito por ativistas feministas, que o enxergavam como um termo aparentemente neutro e desprovido de propósito ideológico imediato, o que é questionado vivamente por aquela historiadora (Scott, 1992, p.64-65). Chegamos assim à atualidade, na qual a divergência de posições, os debates e controvérsias marcam o cenário; quadro que se nos afigura dos mais promissores, e que coincide com a diversidade de correntes presentes na historiografia atual. Diversidade que se manifesta na existência de vertentes que enxergam a teoria como ferramenta indispensável à construção do conhecimento histórico sobre as mulheres, até as que relativizam a sua presença, em nome do caráter fluido, ambíguo, do tema em foco: as mulheres como seres sociais. Ênfase na utilização da categoria 'gênero' na análise da esfera da política formal, em termos do exercício do voto e manejo do poder nas instituições do governo; preferência pela abordagem do cotidiano, "re-descoberta de papéis informais, de situações inéditas e atípicas" que possibilitem o desvendamento de processos sociais invisíveis, ante uma perspectiva normativa.

Essas são algumas das diferentes posturas no tocante aos estudos sobre as mulheres. Algumas opõem história de gênero e história das mulheres - que, na verdade, caminham para uma interpenetração que impede a abordagem isolada de cada uma destas, às quais se juntam as abordagens sobre gays/lésbicas e sobre masculinidades. Criatividade, sensibilidade e imaginação tornam-se fundamentais na busca de pistas que permitam transpor o silêncio e a invisibilidade, que perduram por tão longo tempo quanto ao passado feminino. Estamos, assim, preparadas para fazer frente àqueles que, na academia, ainda não nos reconhecem como parceiras plenas, tentando relegar-nos a posições periféricas em face do caráter 'secundário' de nossas preocupações. E é no bojo destas questões que estamos vendo ser publicada, pela segunda vez, uma Revista Brasileira de História dedicada à questão da História das Mulhe- 
res e das Relações de Gênero. Dezoito anos depois de 1989, muita coisa mudou. O campo ficou mais definido. Mesmo assim, ainda exige atenção e esforço na busca de legitimidade acadêmica.

\section{NOTAS}

${ }^{1}$ DIAS, Maria Odila Leite da Silva. Quotidiano e poder em São Paulo no século XIX. São Paulo: Brasiliense, 1984; RAGO, Luzia Margareth. Do cabaré ao lar: a utopia da cidade disciplinar, Brasil 1890-1930. Rio de Janeiro: Paz e Terra, 1985; LEITE, Miriam Moreira (Org.). A condição feminina no Rio de Janeiro, século XIX: antologia de textos de viajantes estrangeiros. São Paulo: Hucitec; Rio de Janeiro: Fundação Nacional Pró-Memória, 1984.

2 ESTEVES, Martha de Abreu. Meninas perdidas: os populares e o cotidiano do amor no Rio de Janeiro da Belle Époque. Rio de Janeiro: Paz e Terra, 1989; SOIHET, Rachel. Condição feminina e formas de violência: mulheres pobres e ordem urbana, 1890-1920. Rio de Janeiro: Forense Universitária, 1989; SAMARA, Eni de Mesquita. As mulheres, o poder e a família: São Paulo século XIX. São Paulo: Marco Zero; Secretaria de Estado da Cultura de São Paulo, 1989; ENGEL, Magali. Meretrizes e doutores: saber médico e prostituição no Rio de Janeiro (1840-1890). São Paulo: Brasiliense, 1989.

${ }^{3}$ DIAS, Maria Odila Leite da Silva. Teoria e método dos estudos feministas: perspectiva histórica e hermenêutica do cotidiano. In: COSTA, Albertina; BRUSCHINNI, Cristina (Org.). Uma questão de gênero. Rio de Janeiro: Rosa dos Tempos; São Paulo: Fundação Carlos Chagas, 1992. p.39-53; SAMARA, Eni de Mesquita; SOIHET, Rachel; MATOS, Maria Izilda S. de. Gênero em debate: trajetórias e perspectivas na historiografia contemporânea. São Paulo: Educ, 1997; MATOS, Maria Izilda S. de. Estudos de gênero: percursos e possibilidades na historiografia contemporânea. Cadernos Pagu, v.11, p.67-75, 1998; SOIHET, Rachel. História das mulheres e história do gênero. Um depoimento. Cadernos Pagu, v.11, p.77-87, 1998; RAGO, Margareth. Descobrindo historicamente o gênero. Cadernos Pagu, v.11, p.89-98, 1998; RAGO, Margareth. Epistemologia feminista, gênero e história. In: PEDRO, Joana Maria; GROSSI, Miriam Pillar. Masculino, feminino, plural: gênero na interdisciplinaridade. Florianópolis: Ed. Mulheres, 1998. p.21-41; PEDRO, Joana Maria. Relações de gênero na pesquisa histórica. Revista Catarinense de História, n.2, p.35-44, 1994. COSTA, Suely Gomes. Gênero e História. In: ABREU, Martha; SOIHET, Rachel (Org.). Ensino de História: conceitos temáticos e metodologia. Rio de Janeiro: Casa da Palavra, 2003; PEDRO, Joana Maria. Traduzindo o debate: o uso da categoria gênero na pesquisa histórica. Revista História. São Paulo: Ed. Unesp, v.24, n.1, p.77-98, 2005; SOIHET, Rachel. História, mulheres, gênero: contribuições para um debate. In: AGUIAR, Neuma (Org.). Gênero e Ciências Humanas: desafio às ciências desde a perspectiva das mulheres. Rio de Janeiro: Rosa dos Tempos, 1997. p.95-114; SOIHET, Rachel. História das mulheres. In: CARDOSO, Ciro Flamarion; VAINFAS, Ronaldo. Dominios da História. Ensaios de teoria e metodologia. 1.ed. Rio de Janeiro: Campus, 1997. 
${ }^{4}$ Neste texto, contrariando a gramática da língua portuguesa, usaremos os plurais no feminino quando incluírem palavras masculinas e femininas. Fazemos isto para apontar a contingência das regras gramaticais, que estabelecem o masculino como o plural e o universal.

${ }^{5}$ FOX-GENOVESE, Elizabeth. Cultura e consciência na história intelectual das mulheres européias. In: The journal of Women in culture and society, Printed by the University of Chicago, v.12, n.31, p.529-547, 1987.

${ }^{6}$ SCOTT, Joan. História das mulheres. In: BURKE, Peter (Org.). A escrita da História: novas perspectivas. São Paulo: Ed. Unesp, 1992. p.62-95; PERROT, Michelle. Quinze ans d'Histoire des femmes. Sources Travaux Historiques, n.12, 1987.

${ }^{7}$ MUNERATO, Elice. SBPC- elas terão centro de estudos. Opinião, 25 jul. 1975, p.22.

${ }^{8}$ FRIEDAN, Betty. Mística feminina. Rio de Janeiro: Vozes, 1971.

9 STOLCKE, Verena. La mujer es puro cuento: la cultura del género. Estudos Feministas, v.12, n.2, p.92, 2004.

${ }^{10}$ São muitas as obras das autoras e autores citadas/os; entre estas, destacamos: PERROT, Michelle. Mulheres públicas. São Paulo: Ed. Unesp, 1998; DUBY, Georges; PERROT, Michelle. As mulheres e a história. Lisboa: Ed. Dom Quixote, 1995; THÉBAUD, Françoise. Quand nos grand-mères donnaient la vie: la maternité en France dans l'entre-deux-guerres. Lyon: Presses Universitaires de Lyon, 1986; SCOTT, Joan W. A cidadã paradoxal: as feministas francesas e os direitos do homem. Florianópolis: Ed. Mulheres, 2002; DAVIS, Natalie Zemon. Nas margens: três mulheres do século XVII. São Paulo: Companhia das Letras, 1997; HAHNER, June E. Emancipação do sexo feminino: a luta pelos direitos da mulher no Brasil. 1850-1940. Florianópolis: Ed. Mulheres; Santa Cruz (RS): Edunisc, 2003.

${ }^{11}$ RAGO, Luzia Margareth, cit., 1985; LEITE, Miriam Moreira (Org.), cit., 1984; ALGRANTI, Leila Mezan. Honradas e devotas: mulheres da colônia, condição feminina nos conventos e recolhimentos do sudeste do Brasil, 1750-1822. Rio de Janeiro: J. Olympio; Brasília: Ed. UnB, 1993; ESTEVES, Martha de Abreu, cit., 1989; SOIHET, Rachel. Condição feminina e formas de violência: mulheres pobres e ordem urbana, 1890-1920. Rio de Janeiro: Forense Universitária, 1989; DIAS, Maria Odila Leite da Silva. Quotidiano e poder em São Paulo no século XIX. São Paulo: Brasiliense, 1984; DEL PRIORE, Mary. Ao sul do corpo: condição feminina, maternidade e mentalidades no Brasil Côlonia. Rio de Janeiro: J. Olympio; Brasília: Ed. UnB, 1993; DEL PRIORE, Mary. História das mulheres no Brasil. São Paulo: Contexto; Unesp, 1997; FIGUEIREDO, Luciano. O avesso da memória: cotidiano e trabalho da mulher em Minas Gerais no século XVIII. Rio de Janeiro: J. Olympio; Brasília: Ed. UnB, 1993; SAMARA, Eni de Mesquita. As mulheres, o poder e a família: São Paulo século XIX. São Paulo: Marco Zero; Secretaria de Estado da Cultura de São Paulo, 1989; PEDRO, Joana Maria. Mulheres honestas e mulheres faladas: uma questão de classe. Florianópolis: Ed. UFSC, 1998; SOUZA, Maria Lúcia de Barros Mott de Melo. Parto, parteiras e parturientes: Mme Durecher e sua época. Tese (Doutorado em História) - FFLCH, USP, São Paulo, 1998; PARENTE, Temis Gomes. O avesso do silêncio: vivências cotidianas das mulheres do século XIX. Goiânia: Ed. UFG, 2005; POSSAS, Lídia M. V. Mulheres, trens e 
trilhos: modernidade no sertão paulista. Bauru (SP): Edusc, 2001; MENEZES, Lená Medeiros de. Os estrangeiros e o comércio do prazer nas ruas do Rio. Rio de Janeiro: Arquivo Nacional, 1992; COSTA, Suely Gomes. Metáforas do tempo e do espaço doméstico. Rio de Janeiro, século XIX. Tese (Doutorado) - UFF, Niterói, 1996.

${ }^{12}$ Não temos a intenção de arrolar todos os nomes das historiadoras e historiadores que têm escrito sobre história das mulheres no Brasil.

${ }^{13}$ SCHPUN, Mônica Raisa. L'histoire des femmes et du genre au Brésil: enquête sur trois générations. Clio - Histoire, femmes et sociétés, Toulouse: Presses Universitaires du Mirail, n.19, p.193-207, 2004.

${ }^{14}$ Além de Maria Odila, Mônica Schpun destaca outras historiadoras que têm sido responsáveis pela formação de novas pesquisadoras, entre elas Rachel Soihet, Mary Del Priore, Cristina Scheibe Wolff, Margareth Rago e Joana Maria Pedro. Eu acrescentaria, ainda, Maria Izilda Matos, Eni de Mesquita Samara, Ismênia de Lima Martins, Cleci Favaro, Marlene de Faveri, Durval de Albuquerque Júnior e Tania Navarro-Swain, entre outras.

${ }^{15}$ SCOTT, Joan. Gênero: uma categoria útil de análise histórica. (Trad. Christine Rufino Dabat e Maria Betânia Ávila). Recife: SOS Corpo, 1991. p.1-2.

${ }^{16}$ SCOTT, Joan W. Prefácio a Gender and Politics of History. Cadernos Pagu, n.3, Desacordos, desamores e diferenças. Campinas: Pagu - Núcleo de Estudos de Gênero, 1994. p.16.

${ }^{17}$ FAVARO, Cleci Eulália. Imagens femininas. Contradições, ambivalências e violências. Porto Alegre: Edipucrs, 2002.

${ }^{18}$ SOIHET, Rachel. Violência simbólica. Saberes masculinos e representações femininas. Estudos Feministas, v.5, n.1, p.7-29, 1997.

${ }^{19}$ RAMOS, Maria Bernardete. O Brasil dos meus sonhos: feminismo e modernismo na utopia de Adalzira Bittencourt. Estudos Feministas, v.10, n.1, p.11-37, 2002.

${ }^{20}$ PETERSEN, Aurea Tomatis. Trabalhando no banco: trajetória de mulheres gaúchas desde 1929. Tese (Doutorado em História) - PUC/RS, Porto Alegre, 1999.

${ }^{21}$ FAVERI, Marlene de. Memórias de uma (outra) guerra. Cotidiano e medo durante a Segunda Guerra em Santa Catarina. Florianópolis: Ed. UFSC; Itajaí (SC): Univali, 2004.

${ }^{22}$ RAGO, Margareth. Entre a história e a liberdade: Luce Fabbri e o anarquismo contemporâneo. São Paulo: Ed. Unesp, 2001; MATOS, Maria Izilda Santos de. Meu lar é o botequim: alcoolismo e masculinidade. São Paulo: Cia. Ed. Nacional, 2001; WOLFF, Cristina Scheibe. Mulheres da floresta: uma história do Alto Juruá - Acre (1890-1945). São Paulo: Hucitec, 1999; NECKEL, Roselane. Pública vida intima: a sexualidade nas revistas femininas e masculinas (1969-1979). Tese (Doutorado em História) - PUC/SP, São Paulo, 2004; SCHPUN, Mônica Raisa. Les années folles à São Paulo: hommes et femmes au temps de l'explosion urbaine (1920-1929). Paris: L'Harmattan, 1997; NAVARRO-SWAIN, Tania. Entre a vida e a morte, o sexo. Labrys - Études féministes / Estudos feministas, Brasília, Montréal, Paris, v.10, jul.-dez., 2006. 
${ }^{23}$ ALBUQUERQUE JÚNIOR, Durval Muniz. Nordestino - uma invenção do falo. Uma história do gênero masculino (Nordeste - 1920-1940). Maceió: Catavento, 2003.

${ }^{24}$ ST. HILAIRE, Colette. A dissolução das fronteiras do sexo. In: NAVARRO-SWAIN, Tania et al. (Org.). Feminismos, teorias e perspectivas. Brasília: Ed. UnB, 2000. p.89.

${ }^{25}$ LAQUEUR, Thomas. Inventando o sexo: corpo e gênero dos gregos a Freud. Rio de Janeiro: Relume Dumará, 2001.p.23.

${ }^{26}$ BUTLER, Judith. Problemas de gênero. Feminismo e subversão da identidade. Rio de Janeiro: Civilização Brasileira, 2003.p.25.

${ }^{27}$ PISCITELLI, Adriana. Reflexões em torno do gênero e feminismo. In: COSTA, Claudia de Lima; SCHMIDT, Simone Pereira. Poéticas e políticas feministas. Florianópolis: Ed. Mulheres, 2004. p.54-55.

${ }^{28}$ NAVARRO-SWAIN, Tania. A invenção do corpo feminino ou a hora e a vez do nomadismo identitário? Textos de História, Brasília: Ed. UnB, v.8, n.1-2, p.47-84, 2000.

${ }^{29}$ NICHOLSON, Linda. Interpretando o Gênero. Revista Estudos Feministas, Florianópolis: Centro de Filosofia e Ciências Humanas - UFSC, v.8, n.2, p.9-41, 2000.

${ }^{30}$ RUBIN, Gayle. The Traffic of Women. In: REITER, R. R. (Org.). Toward an Anthropology of Women. New York: Monthly Review Press, 1975. p.159.

${ }^{31}$ COSTA, Claudia de Lima. O tráfico do gênero. Cadernos Pagu, Campinas: Ed. Unicamp, v.11, p.127-140, 1998. p.138.

Artigo recebido em dezembro de 2007. Aprovado em dezembro de 2007. 